fair judgment of him, we must not be put off by the barbarous traits he shares with his time: belief in the conformity of shapes and therapeutic properties of plants, or in the reality of phenomena associated with magic and sorcery. Disconcerting as this may seem, if he includes these things in his treatise on qualities, it is with a rationalistic intention: he fights superstition by rationalizing it; he exorcises the demons by reducing their workings to natural causes. As to astrological predictions, he deprives them of any real foundation by an ingenious argument: because the periods of the heavenly motions are incommensurable, no celestial configuration will ever repeat itself, and the alleged regularities on which the astrologers base their horoscopes are therefore spurious.

Oresme's rationalistic turn of mind applied itself, of course, also to more concrete objects. His familiarity with the optical writings of Robert Grosseteste and Witelo, to which he owed the suggestion of his graphical method (they represented beams of light by cones whose opening indicated the intensity of illumination), reveals an early interest for the study of natural phenomena, which especially Grosseteste and his disciple Roger Bacon endeavoured to foster among the clerics. Oresme's later participation in the affairs of the realm appears indeed as a fulfilment (however modest) of Roger Bacon's vision of a philosophy serviceable to the useful arts: we find an echo of this aspiration in the prologues of Oresme's French writings, which were addressed directly to the merchants, the "mechanics", the King's civil servants. Yet it could not escape such clear-sighted men as Oresme and his best disciple Henry of Hesse how insufficient the scholastic way of thinking was to cope with real problems, how powerless its formal approach leaves us in front of practical tasks: one perceives in the parts of their writings dealing with natural phenomena an undertone of scepticism and disillusion.

We are here touching on one of the most challenging problems of the history of science. Why did the rationalistic tendencies within the scholastic philosophy ultimately come to nothing? Why did the fire not catch, but remain a mere flicker in the darkness ? Clagett is certainly right to point to the intrinsic weakness of the scholastic method as a cause of the decay which set in so soon after Oresme's promising start; but it is not the only one. The schoolmen's pathetic failure must be seen in the perspective of the general crisis which swept away the whole social structure of the middle ages; both the intellectual and the economic aspects of the case must be taken into account. For such a study abundant material is at hand, but historians of science do not seem too keen to analyse it. It is of course more polite, and safer, to bestow praise on the thinkers of the past than to expose their failings; and polite reviewers encourage historians to believe that nothing else is expected of them. Thus the legend of the continuous progress of science is kept alive, and the history of the most spectacular defeat of human reason remains unwritten.

L. ROSENFELD

\section{ATOMIC COLLISIONS}

\section{The Observation of Atomic Collisions in Crystalline Solids}

(Defects in Crystalline Solids, Vol. 1.) By R. S. Nelson. Pp. $\mathrm{x}+281$. (North-Holland: Amsterdam, 1968.) 117s. ONE has only to hold and turn in one's hands a model of any crystal lattice to appreciate that there are certain "open" directions which might allow the passage of a particle with weak interaction with the atoms of the lattice, and there are directions in which a particle could not penetrate far into the lattice without suffering a large deflexion through collision with a lattice atom. The possibility of channelling, in which a particle is confined within an open region of a lattice by successive deflexions towards the channel axis by atoms in densely packed rows or planes surrounding the open region, was first suggested by J. Stark in 1912. His idea was forgotten and, until the beginning of the present decade, little serious effort was devoted to exploring the theoretical or practical implications of channelling. Recent years have seen, however, a very large number of experiments, some of great beauty and refinement, and the development of theoretical models for their interpretation. The author of this book, who has himself made a considerable contribution in this field, has sought to provide an introduction to the field and to present an orderly account of the experimental work up to the time of writing. He has succeeded admirably.

After short introductory chapters on the interaction of radiation with matter and on some of the specially developed experimental techniques, the main chapters cover channelling; the collision cascade initiated by the collision of a primary particle with a lattice atom; and a discussion of sputtering which occurs when a collision cascade intersects a crystal surface. There is pointed out the obvious relevance of channelling to the technology of ion implantation as a means of producing a doped region in a semiconductor. Moreover, a detailed examination of the scattering of protons by doped semiconductor samples may differentiate between the occupation by the impurity atoms of substitutional or interstitial sites. The behaviour of the unchannelled or random component of a beam of high energy particles is also modified by the ordering of the lattice, which causes blocking of particles which undergo Rutherford scattering into densely packed planes. The blocking pattern is shown to appear as a projection of these planes. Because of small penetration this is a useful method for the examination of the structure of epitaxial layers. The development of the theory of focused collision sequences will be of interest to those concerned with mechanisms of radiation damage, as these provide a method by which separated interstitial and vacancy pairs may be produced.

The value of this book, the first in a series on defects in crystalline solids, is enhanced by the lavish and effective use of illustrations. A later volume will discuss collision theory, which is here given rather briefly and rather too concisely to be easily followed by a newcomer to the field. The author has managed to convey something of the spirit of good experimental science and, for this reason, deserves a wider readership than the specialists for whom the book has been written.

T. P. P. HALL

\section{MOLECULAR MIGRATIONS}

\section{Mechanisms of Molecular Migrations}

Vol. 1. Edited by B. S. Thyagarajan. Pp. ix +331 . (Interscience (Wiley): New York and London, January 1969.) 164s.

SKELETAL rearrangements of organic molecules, particularly those which take place under relatively mild conditions, have intrigued chemists ever since they were first recognized early in the history of organic chemistry. The diversity of these transformations, their value in synthetic chemistry, and the challenges they present to unravelling their mechanisms, have served to stimulate considerable interest and research. Frequently, reviews have appeared on particular rearrangements, but although such reviews summarize knowledge at the time they are written, these individual efforts have appeared over a period of many years, thereby reducing their total effectiveness. From this point of view, the production of a series, Molecular Rearrangements ${ }^{1}$, had much to commend it because a wide area of molecular transformations was substantially reviewed at one time. In such a relatively limited work it is clear, however, that many molecular migrations can receive only scant attention, and detailed 